\title{
Identificação de entrada de plumas de queimada e principais áreas afetadas na região Sul do Brasil
}

\author{
Identification of entrance of burning plumes and main affected areas in southern \\ Brazil
}

\author{
Aline Macedo de Oliveira ${ }^{1}$, Glauber Lopes Mariano ${ }^{2}$ \\ 1,2 Universidade Federal de Pelotas, RS, Brasil
}

\begin{abstract}
Resumo
A região Sul do Brasil sofre a influência de entradas de plumas de queimadas das regiões Norte e Centro-Oeste do Brasil. O objetivo deste trabalho é identificar entradas de plumas de aerossóis de queimadas na região Sul do Brasil assim como as épocas com maiores valores de Espessura Óptica dos Aerossóis (EOA) e as áreas mais afetadas por aerossóis atenuadores na região Sul do Brasil. Utilizou-se dados de EOA e Expoente de Angstrom (EA) obtidos através do sensor MODIS (MODerate- Resolution Imaging Spectroradiometer) a bordo do satélite AQUA no comprimento de onda de 0,55 um para a EOA e de 0,47 a 0,66 um para o EA no período de 2002 a 2011. Observouse que os aerossóis dominantes na atmosfera da região Sul do Brasil são pouco atenuadores de radiação (com baixos valores de EOA), porém há casos com valores elevados de EOA o que indica a presença de partículas atenuadoras de radiação. Além disto, foi observado que os casos com valores elevados de EOA ocorreram entre o inverno e a primavera, principalmente na região noroeste da área de estudo.
\end{abstract}

Palavras-chave: MODIS, Espessura Óptica dos Aerossóis, queimadas

\begin{abstract}
Southern Brazil is influenced by incoming biomass burning plumes from Northern and Midwest of Brazil. The aim of this work is to identify incoming biomass burning aerosol plumes in southern Brazil as well as the periods with the higher values of Aerosol Optical Thickness (AOT) and the areas more affected by attenuator aerosols in Southern Brazil. The MODIS (MODerate- Resolution Imaging Spectroradiometer) sensor data onboard of

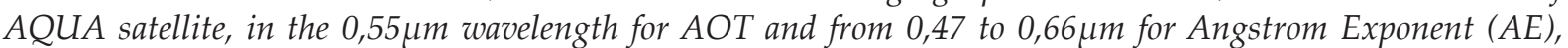
were used from 2002 to 2011. It was observed that the predominant aerosol on Southern Brazil's atmosphere were low radiation attenuators (with low values of $A O T$ ). However, there are cases with high $A O T$ values indicating the presence of particles of radiation attenuators. Furthermore it was observed that the cases of high AOT values occurred between winter and spring, mostly at the northwest of the studied area.
\end{abstract}

Keywords: MODIS, Aerosol Optical Thickness, biomass burning 


\section{Introdução}

Os aerossóis influenciam o clima como resultado de seus efeitos na radiação (através dos efeitos direto e indireto que são responsáveis por refletir e absorver radiação e agir nas propriedades radiativas das nuvens, respectivamente), aquecendo ou resfriando a superfície. Entretanto, isto vai depender da refletividade que está relacionada com as características de absorção e espalhamento de uma camada de aerossóis (ARTAXO et al., 2006; AROLA et al., 2007). Os aerossóis são uns dos principais vetores da poluição atmosférica e participam de diversos fenômenos naturais. Têm como principais fontes emissoras: emissões vulcânicas, poeira transportadas pelo vento, processos de combustão entre outros (ALMEIDA, 2009).

Uma forma de se conhecer o tipo de aerossol presente na atmosfera é caracterizá-los opticamente (KAUFMAN, et al. 2002). O Expoente de Angstrom (EA) correlaciona o tamanho da partícula com seu tipo. Portanto, o valor médio do EA pode determinar o tipo de partícula predominante presente em um determinado caminho óptico na atmosfera. Juntamente com o EA, a Espessura Óptica dos Aerossóis (EOA) complementa as informações sobre o tipo de aerossol, uma vez que é utilizada para determinar as propriedades das partículas. Sua natureza espectral é determinada pelas fontes de aerossol além de outros processos atmosféricos, é dependente do comprimento de onda e é adimensional (SCHUSTER et al, 2006). Kaskaoutis et al. (2007) analisaram quatro lugares do planeta: Brasil, Arábia Saudita, Itália e Nauru (ilha do Pacífico) a fim de se caracterizar o tipo de partícula predominante em cada região citada. Através da correlação entre a EOA e o EA foi possível caracterizar os aerossóis dominantes em cada localidade como de queima de biomassa, poeira, poluição urbana e marinha, respectivamente.

Na América do Sul a principal fonte emissora de partículas de aerossóis são as queimadas de florestas e cerrados, que ocorrem principalmente durante a estação seca (de julho a outubro) nas regiões Amazônica e Centro - Oeste (POSSANI et al., 2006). As emissões da região Amazônica, devido à intensa atividade convectiva, lançam os aerossóis para longas distâncias causando um impacto não só local, mas também global (ARTAXO e HANSSON, 1995). Diversos autores estudaram o transporte de partículas de aerossóis oriundos da região Amazônica para diferentes partes da América do Sul e do globo. Freitas et al. (1996), Longo et al. (1998) e Assunção (2006) analisaram o transporte de plumas de aerossóis em diferentes situações mas com todas apresentando deslocamento da região Norte para a região Sul do Brasil. Os autores observaram que as plumas de aerossóis de queimada com origem no Brasil Central são transportadas para oeste, sobre os Andes em direção ao Oceano Pacífico Tropical assim como para o sul da
América do Sul e depois para leste em direção ao Oceano Pacífico Subtropical.

Além destes, Recuero et al. (2004) analisaram o transporte de plumas de aerossóis durante a estação seca em 2002, nas regiões do Ji-Paraná e Brasil Central, para algumas regiões da América do Sul. Neste estudo foi observado que na presença da Alta Subtropical do Atlântico Sul (ASAS) posicionada entre as regiões nordeste e sudeste, a pluma é transportada para a região Sul do Brasil. Na presença de um sistema de alta pressão (sobre o estado de São Paulo), a pluma acopla-se a este sistema e segue em direção ao Oceano Atlântico. Haag e Krenzinger (2010) observaram que durante a estação seca na Amazônia, época em que ocorrem os maiores índices de queimadas, os valores máximos de EOA no comprimento de onda de $0,55 \mu \mathrm{m}$, obtidos através do sensor MODIS (MODerate- Resolution Imaging Spectroradiometer), foram em torno de 0,9 no Centro- Oeste do Brasil, Bolívia e Paraguai, no Rio Grande do Sul o valor máximo identificado no mês de setembro foi de 0,2 . Ulke (2007) analisou o transporte de aerossóis na presença de um Jato de Baixos Níveis (JBN) que levou o material particulado da Amazônia para o Rio Grande do Sul e observou que os altos valores de EOA estavam relacionados com o mínimo no núcleo do jato. Ainda foi observado que os altos valores de EOA tiveram origem das queimas de biomassa. Ulke (2009) relacionou o transporte de aerossóis de dois eventos de jato, o SALLJ (South America Low Level Jet, Jato de Baixos Níveis da América do Sul) e o CJ (Chaco Jet, Jato do Chaco). Foram observados 30\% de eventos de SALLJ e 35\% de CJ, na ocorrência destes, o valor médio da EOA foi de 0,12 e do EA foi de 1,12. Também foi observado um aumento de EOA durante eventos de CJ, acordando com a presença de maior carga de aerossóis. Como conclusão, relacionou-se o alto valor de EA com a presença de aerossóis de queima de biomassa, pois valores elevados de EA indicam a presença de partículas com material particulado do tipo fino, característica de aerossóis de queimadas.

Além da presença de aerossóis transportados de outras regiões, a região Sul do Brasil sofre influência de partículas locais tais como de poluição urbana, que podem influenciar a quantidade de partículas presentes na atmosfera. Além disto, devido sua localização, adjacente ao oceano Atlântico e próxima ao oceano Pacífico, faz com que ela sofra influência de aerossóis marinhos. Considerando estas informações, o estudo a cerca do tipo de partícula em suspensão na atmosfera da região se faz necessário, já que há poucos trabalhos deste tipo realizados para a região Sul do Brasil. Desta forma o objetivo deste trabalho é identificar as épocas com maiores valores de EOA e EA além das áreas mais afetadas por aerossóis atenuadores de radiação. 


\section{Metodologia}

\section{1 Área de estudo e dados}

A região Sul inclui os estados do Paraná, Santa Catarina e Rio Grande do Sul, possui população de aproximadamente 27.386.891 habitantes sendo a menor das regiões do país. É a segunda região mais industrializada devido a atividades diversificadas, como refinarias de petróleo, agricultura, exploração de carvão, entre outras (IBGE, 2010). A Figura 1 corresponde a América do Sul e o retângulo em vermelho a região Sul do Brasil (área de estudo) e áreas adjacentes: leste da Argentina e Paraguai, sul do Mato Grosso do Sul, norte do Uruguai e oeste do Oceano Atlântico. As regiões adjacentes são consideradas por influenciarem, de forma significativa, os resultados esperados.

Utilizou-se dados do sensor MODIS a bordo do satélite AQUA para a análise da EOA no comprimento de onda de $0,55 \mu \mathrm{m}$ e EA nos comprimentos de onda de 0,47 a 0,66 $\mu \mathrm{m}$, de 2002 a 2011. Os dados utilizados são de Nível 3 (MYD08_D3), ou seja suas variáveis são mapeadas em grades igualmente espaçadas, com preenchimento consistente e com aplicação de filtro para remoção de pixeis com detecção de nuvens (contaminados). Têm resolução

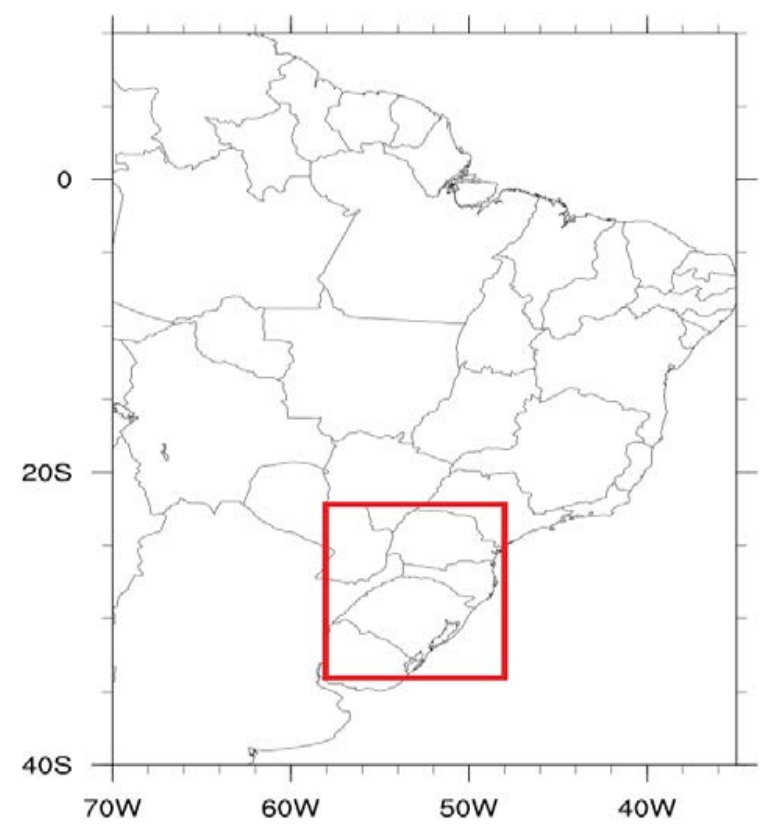

Figura 1 - Área de estudo.

espacial de $1^{\circ} \times 1^{\circ} \mathrm{km}$ e resolução temporal diária em um intervalo de 00- 24 GMT (Greenwich Mean Time Tempo Médio de Greenwich) (RUDORFF et al, 2007).

\subsection{Análise da Espessura Óptica dos Aerossóis (EOA) e Expoente de Angstrom (EA)}

Neste trabalho utilizou-se a EOA para determinar o tipo de aerossol em suspensão na atmosfera da região Sul do Brasil, através da análise do percentil 99 (P99). O cálculo do P99 foi empregado para determinar os casos com valores elevados de EOA e o período em que estes ocorreram. Além da EOA, utilizou-se o EA para determinar o tamanho das partículas presentes na atmosfera. A análise das duas variáveis (EOA e EA) determinou o tipo de aerossol dominante na atmosfera da região Sul, já que para se ter uma boa caracterização das propriedades dos aerossóis, ou seja, ter um conhecimento do aerossol dominante, a análise das duas variáveis é necessária. A tabela 1 corresponde aos limiares de EOA e EA adotados, para a caracterização do tipo de aerossol, segundo Kaufman (2002) e Schuster et al. (2006):

Tabela 1 - Limiares de EOA e EA adotados para a caracterização dos aerossóis.

\begin{tabular}{c|c|c|c}
\hline EOA $\leq 1,0$ & EOA $>1,0$ & EA $\leq 1,5$ & $\begin{array}{c}1,5 \leq \mathrm{EA} \\
\geq 2,0\end{array}$ \\
\hline $\begin{array}{c}\text { Aerossóis } \\
\text { pouco } \\
\text { atenuadores } \\
\text { de radiação }\end{array}$ & $\begin{array}{c}\text { Aerossóis } \\
\text { atenuadores } \\
\text { de radiação }\end{array}$ & $\begin{array}{c}\text { Aerossóis } \\
\text { de moda } \\
\text { grossa }\end{array}$ & $\begin{array}{c}\text { Aerossóis } \\
\text { de moda } \\
\text { fina }\end{array}$ \\
\hline
\end{tabular}

\section{Resultados e discussões}

\subsection{Análise anual da Espessura Óptica dos Aerossóis e Expoente de Angstrom}

A Figura 2 corresponde aos anos de 2002 a 2011 em que é mostrada a distribuição da EOA e do EA na região de estudo. As linhas na Figura correspondem à mediana do EA (horizontal) e EOA (vertical). Percebe-se, pelos baixos valores de EOA, e pelos valores da mediana (mostrados nas Figuras), que o tipo de aerossol dominante na região é caracterizado como pouco atenuador de radiação, já os altos valores de EA indicam a presença predominante de partículas de moda fina. Entretanto, destacam-se alguns anos em que é possível observar uma maior dispersão dos pontos com valores mais elevados de $\operatorname{EOA}(\mathrm{EOA}>1,0)$, isto indica a presença de aerossóis atenuadores de radiação e de moda fina $(\mathrm{EA}<1,5)$.

Os anos de 2002 (Fig. 2a), 2004 (Fig. 2c), 2007 (Fig. 2f) e 2010 (Fig. 2i) dentre todos os anos do período, foram os anos em que há uma maior dispersão da EOA, como pode ser observado nas Figuras citadas. O aumento da EOA pode ser decorrente do maior número de eventos de queimadas ocorridos nestes anos, segundo dados do grupo de queimadas do CPTEC/INPE (http:// sigma.cptec.inpe.br/queimadas), e que devido à ação do vento, possivelmente transportaram partículas de aerossóis de queima de biomassa para a região Sul (além dos focos presentes dentro da região). Em 2002 ocorreram 44.891 focos de queimada no Brasil, em 2004: 50.300, 2007: 25.748 e em 2010: 24.929, segundo os satélites de referência AQUA e NOAA-12. 


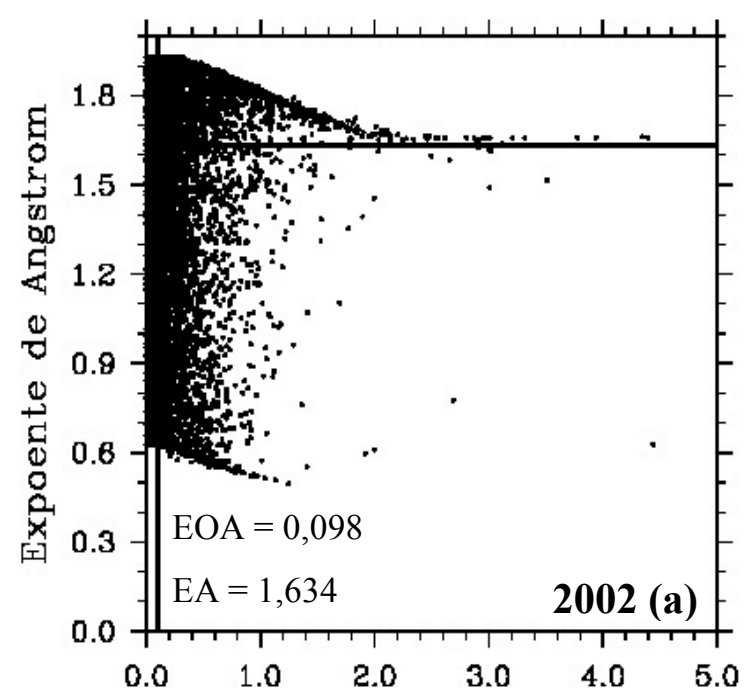

Espessura Optica dos Aerossois

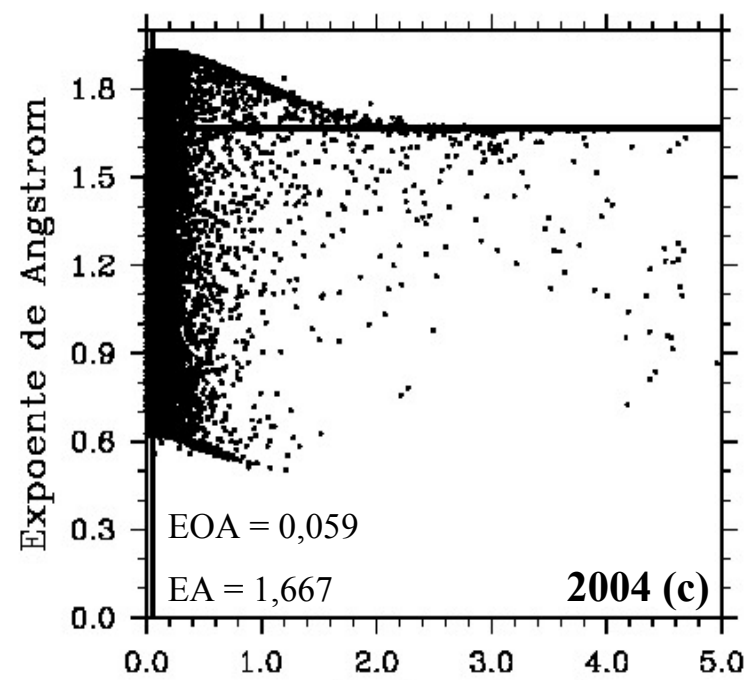

Espessura Optica dos Aerossois

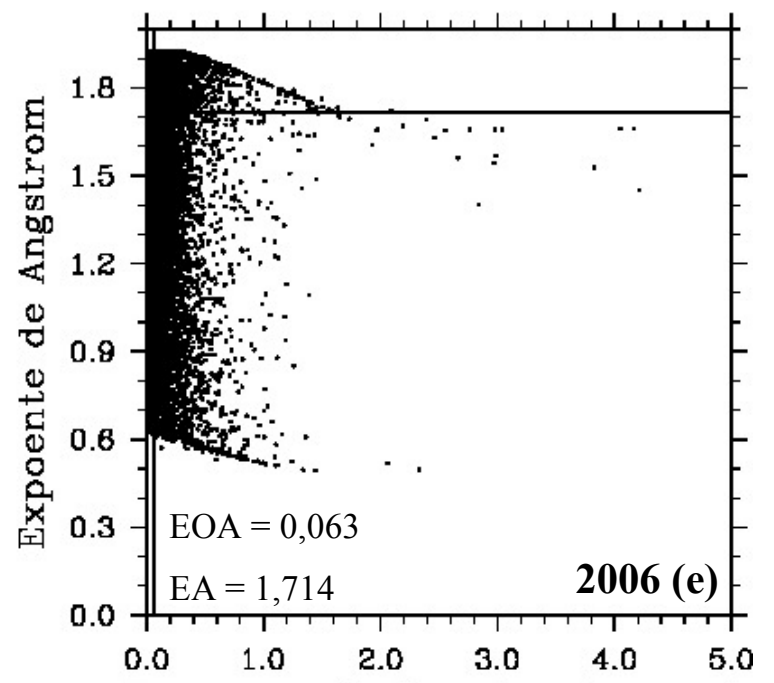

Espessura Optica dos Aerossois

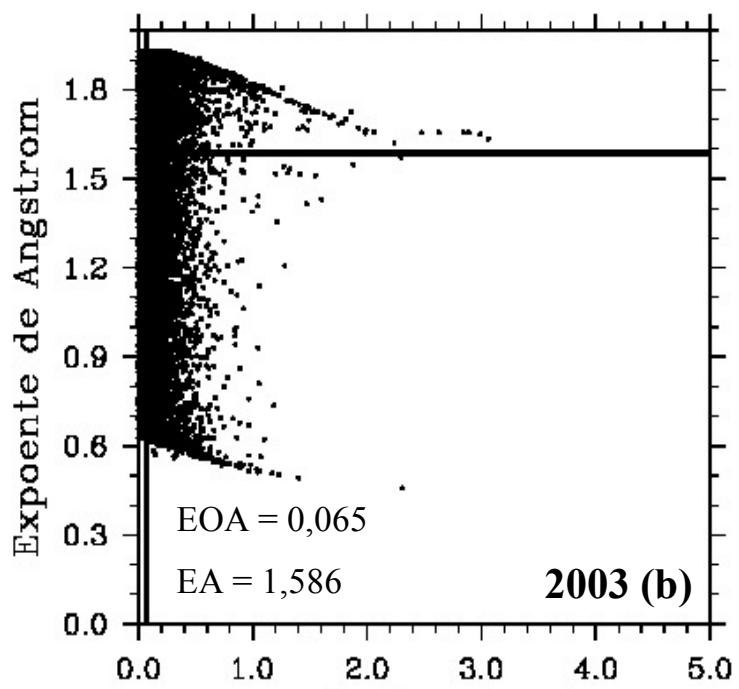

Espessura Optica dos Aerossois

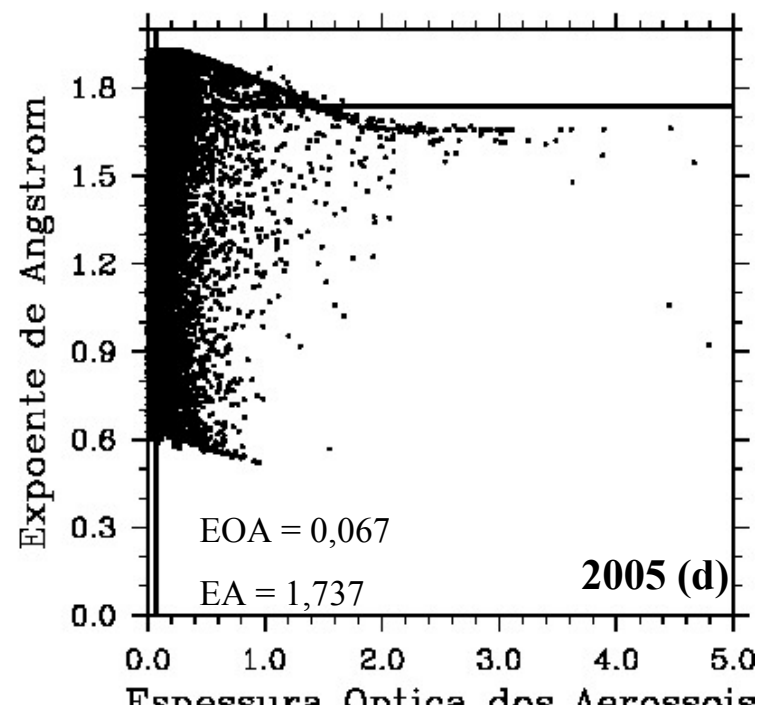

Espessura Optica dos Aerossois

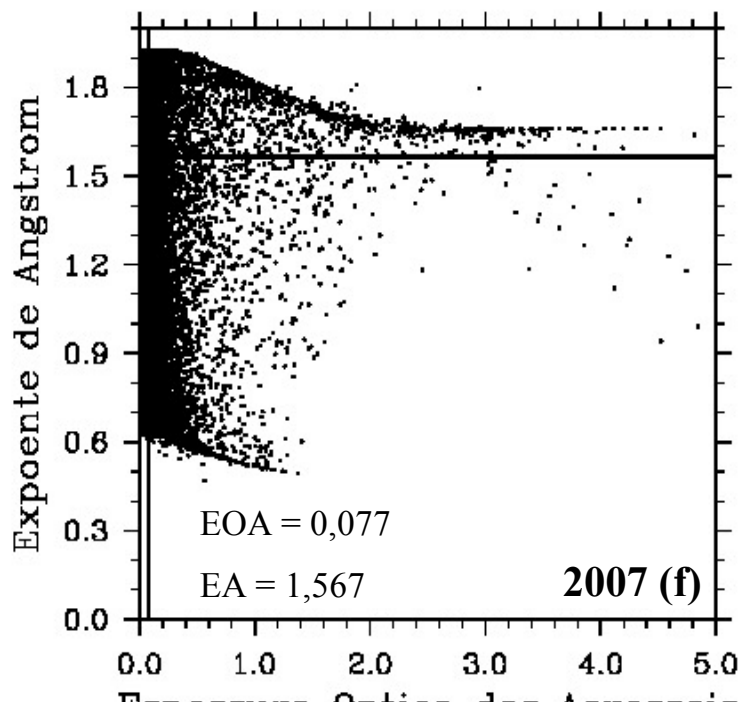

Espessura Optica dos Aerossois

Figura 2 - Expoente de Angstrom versus Espessura Óptica da Atmosfera no comprimento de onda de 0,55 $\mu$ m obtidos pelo sensor MODIS nos anos de 2002 a 2011 (a-j) sobre a região Sul do Brasil. Linhas representam as medianas, cujos valores encontram-se nas Figuras, para o período analisado. 


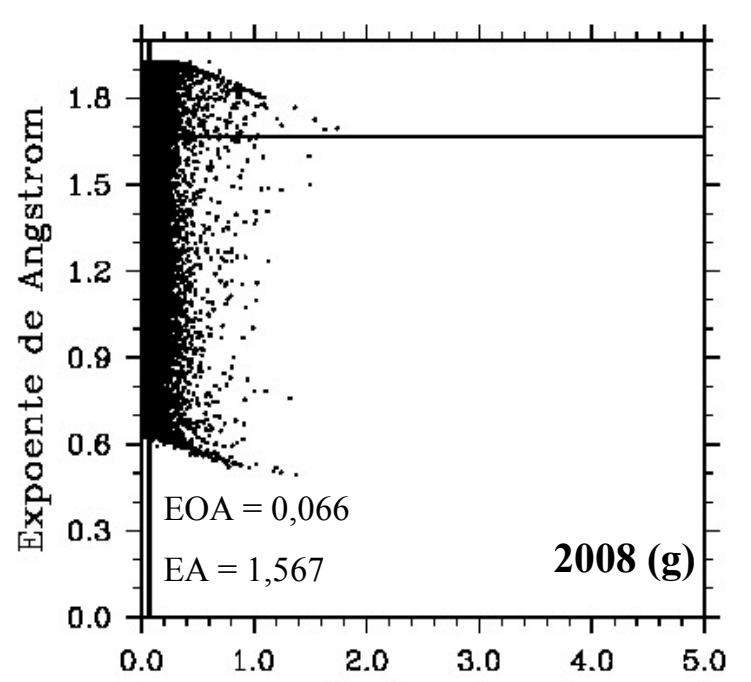

Espessura Optica dos Aerossois

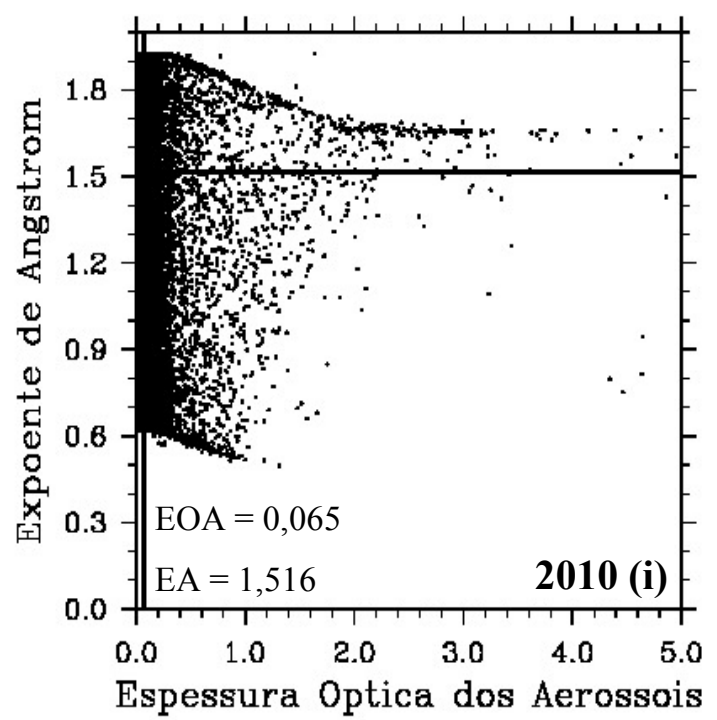

Figura 2 -continuação ....

\subsection{Análise do máximo valor diário da Espes- sura Óptica dos Aerossóis}

A Figura 3 mostra os máximos valores diários da EOA sobre a área analisada. Percebe-se uma variação sazonal dos valores encontrados, não havendo uma continuidade destes durante cada ano. Os maiores valores ocorreram durante o inverno e primavera (aproximadamente a partir do dia 210 até o dia 300) época que ocorrem a maior quantidade de eventos de queimadas na região Norte e Centro - Oeste. Entretanto nos anos de 2008 e 2009 este padrão não foi observado, pois nestes, os números de focos de queimada ocorreram em menor quantidade (12.324 em 2008 e 12.321 em 2009), em comparação aos demais (em média 36.467 focos) dificultando o transporte das partículas para outras regiões.
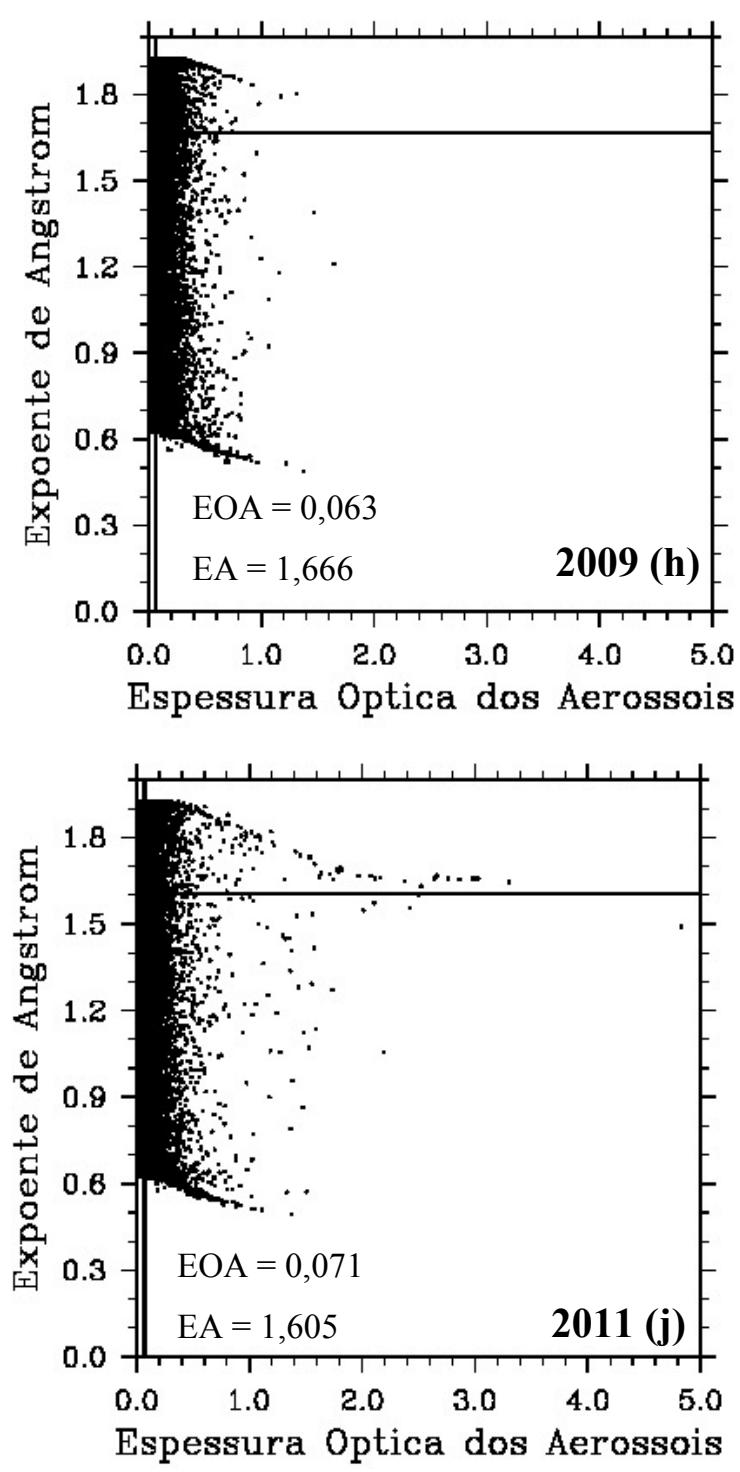

Na maior parte dos anos observa-se que a máxima EOA diária tem valores bastante elevados, o que caracteriza a presença de aerossóis atenuadores de radiação. Considera-se ainda a probabilidade de que a elevação nos valores diários de EOA possa ser decorrente de uma possível deficiência no algoritmo de filtro de nuvens do MODIS. Isto ocorre caso o algoritmo não detecte algum pixel contaminado por nuvem removendo-o e consequentemente elevando os valores de EOA na região. Todavia, uma vez que os dias com valores elevados coincidiram com o período dos maiores índices de queimadas na região Norte, a possibilidade de que, mesmo com a presença de nuvens, o aumento da EOA seja decorrente do transporte associado à circulação de grande escala que advecta as partículas para a região de estudo é elevada. 

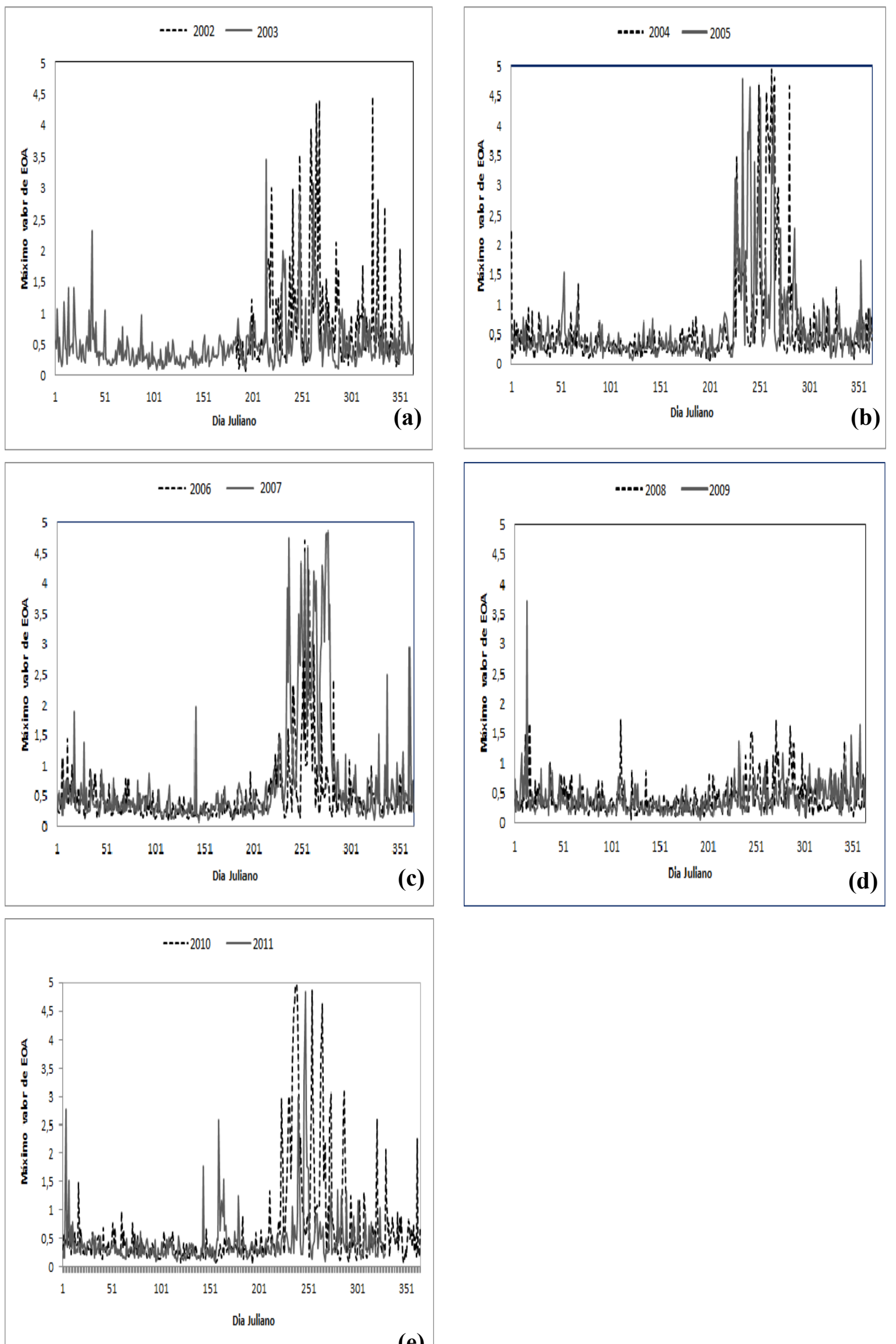

(e)

Figura 3 - Máximo valor diário da Espessura Óptica da Atmosfera dos anos 2002 a 2011 (a-e). 


\subsection{Avaliação do percentil 99}

A Figura 4 corresponde ao percentil 99 (P99) da EOA dos invernos (a) e primaveras (b) - períodos em que ocorreram os maiores valores de EOA - entre 2002 e 2011. No inverno (Fig. 4a) observam-se valores altos do P99 da EOA entre Paraguai e Paraná que variam de 1,2 a 3,5. Devido à localização dos pixeis, é possível que a elevação tenha sido decorrente de entradas de plumas de aerossóis de queimadas de outras regiões, já que durante estas estações ocorrem os maiores índices de eventos de queimada na região Norte do país. Apesar de na primavera ocorrerem altos índices de eventos de queima de biomassa, estes não mostraram influência significativa na análise total das primaveras (Fig. 4b).
A Figura 5 mostra a EOA (a) e o EA (b) do dia 07 de setembro de 2007. A Figura é um exemplo em que observa-se o transporte da partículas com altos valores de EOA da região Norte para a Sul do Brasil. Este dia em particular, foi escolhido por ter ocorrido dentro do período com valores de EOA mais elevados e por apresentar o deslocamento da pluma de forma clara.

A EOA mostra a pluma com deslocamento norte-sul da América do Sul com valores variados em sua extensão. Na região de estudo é possível observar a presença de pontos com valores de EOA elevados, indicando que há partículas altamente atenuadoras de radiação devido ao deslocamento da pluma de queimada. Estes pontos localizam-se, assim como na Figura 4a, a noroeste da área de estudo, havendo uma similariedade entre as
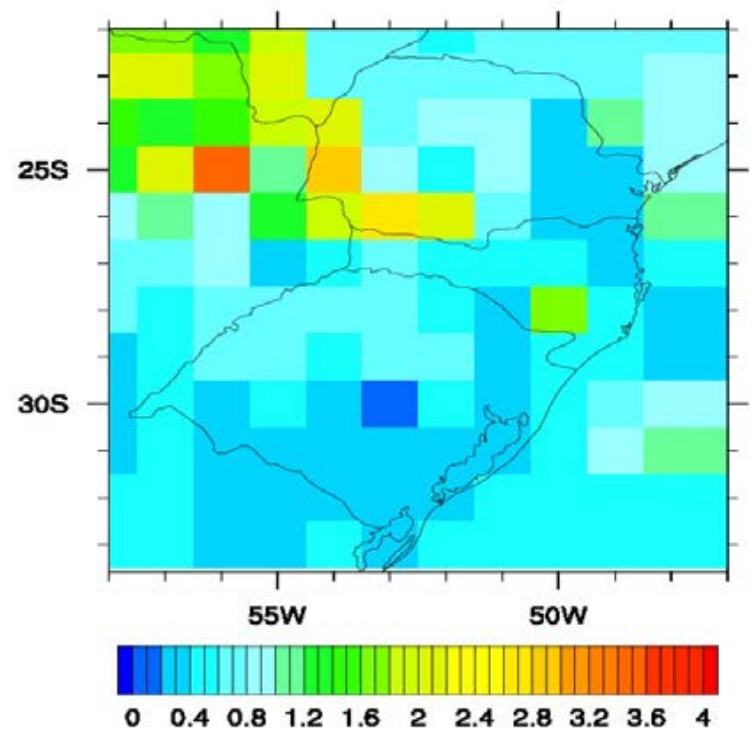

(a)

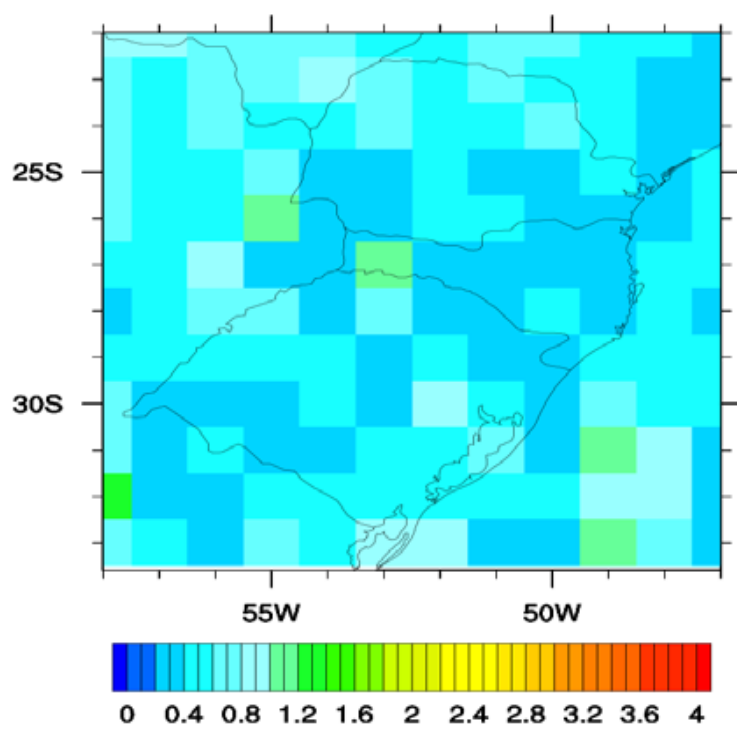

(b)

Figura 4 - Percentil 99 da Espessura Óptica da Atmosfera dos invernos (a) e primaveras (b).
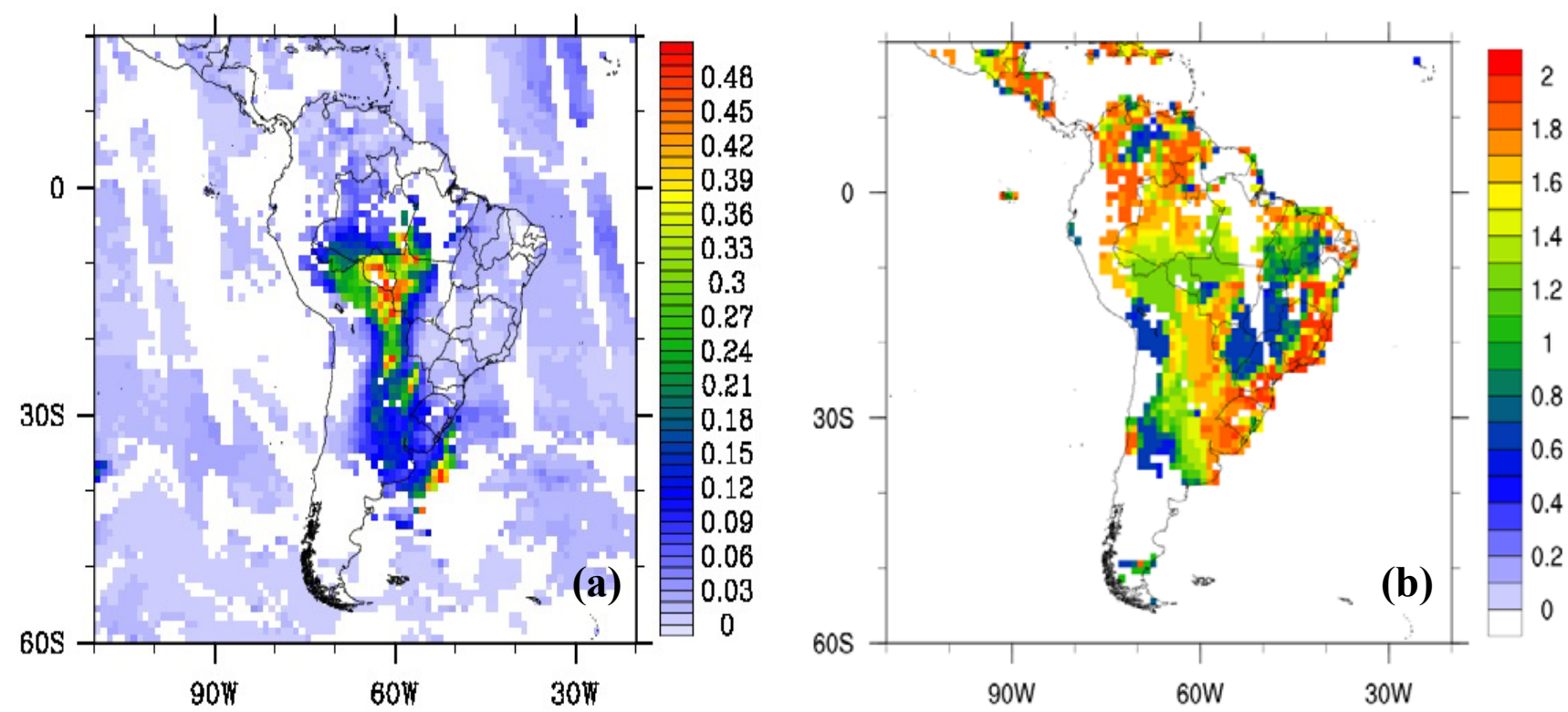

Figura 5 - Espessura Óptica da Atmosfera (a) e Expoente de Angstrom (b) no comprimento de onda de 0,55 $\mu$ m do dia 07 de setembro de 2007. 
duas situações, apesar da diferença temporal entre elas. Isto mostra que o aumento da EOA observado se deu devido ao transporte de aerossóis de queimada com origem na região Norte do Brasil. O EA auxilia esta conclusão, pois apresentou valores elevados (acima de 1,5) em praticamente todos os pontos da pluma, assim como na região de estudo indicando, a presença de partículas de moda fina, uma característica de aerossóis de queimadas.

\section{Conclusões}

O objetivo deste trabalho era de identificar o período e as principais áreas afetadas por entradas de plumas de aerossóis de queimada na região Sul do Brasil por meio dos valores da Espessura Óptica da Atmosfera e do Expoente de Angstrom. O tipo de aerossol predominante na região Sul é caracterizado como pouco atenuador de radiação, com valores de EOA menores que 1,0. Todavia foi observada a presença de casos com valores elevados de EOA, principalmente nos anos de 2002, 2004, 2007 e 2010. Pela análise do valor máximo diário concluiu-se que estes valores ocorreram entre o inverno e a primavera, época em que ocorrem os maiores índices de eventos de queimadas na região Norte do país, o que auxiliou para que o aumento ocorresse.

Assim como na análise do máximo valor diário da EOA, foi observado através do percentil 99 (P99) da EOA, que os maiores valores ocorreram durante o inverno e a primavera. As áreas com valores mais elevados do P99 da EOA situaram-se principalmente, entre o leste da Argentina e Paraguai e oeste do Paraná, noroeste da região de estudo. Nestes casos, o P99 da EOA teve valores entre 1,5 e 4,8, aproximadamente. Devido à localização dos pixeis, certificou-se que a elevação seja decorrente de partículas de queima de biomassa. Desta forma pode-se dizer que a região Sul do Brasil sofre influência de partículas de aerossóis de queimadas advectados de outras regiões, já que os valores elevados de EOA e EA caracterizam aerossóis de queima de biomassa.

\section{Agradecimentos}

A primeira autora gostaria de agradecer a CAPES pela concessão da bolsa de estudo, ao Programa de Pós Graduação em Meteorologia (PPGMet) pela realização do curso de mestrado, a equipe do sensor MODIS pelos dados cedidos gratuitamente para a realização do trabalho. O segundo autor gostaria de agradecer a FAPERGS (processo 11/1687-0) pelo apoio para a realização do projeto de pesquisa.

\section{Referências}

ALMEIDA, A. M. E. ,Aerossol carbonoso: Contribuição para sua caracterização. 2009. Dissertação de mestrado (Departamento de Ambiente e Ordenamento), Universidade de Aveiro.

AROLA, A., LINDFORS, A.; NATUNEN, A.; LEHTINEN, K. E. J. A case study on biomass burning aerosols: effects on aerosol optical properties and surface radiation levels. Atmospheric Chemistry Physics. ,v.7, p. 4257-4266, 2007.

ARTAXO,P.; HANSSON,H. Size distribution of biogenic aerosol particles from the Amazon Basin. Atmospheric Environment. v.29, n.3, p.393-402, 1995

ARTAXO,P.;OLIVEIRA, P. H.; LARA, L. L.;PAULIQUEVIS,T. M.; RIZZO, L. V.; JUNIOR, C. P.;PAIXÃO, M. A.;LONGO, K. M.; FREITAS, S.;CORREIA, A. L. Efeitos climáticos de partículas de aerossóis biogênicos e emitidos em queimadas na Amazônia. Revista Brasileira de Meteorologia, v.21, n.3a, p. 168-220, 2006.

ASSUNÇÃO, M. Meteorologia, Desmatamento e Queimadas na Amazônia: Uma síntese de resultados do LBA. Revista Brasileira de Meteorologia. v.21, n.3a, p.190-199, 2006.

FREITAS, S. R.; LONGO, K. M.; SILVADIAS, M. A. F.; ARTAXO, P. Numerical modeling of air mass trajectories from the biomass burning areas of the Amazon Basin, Anais da Academia Brasileira de Ciências, 68, 1, 1996.

HAAG, R.; KRENZINGER, A. Irradiância solar típica na região amazônica e seu impacto em dispositivos fotovoltaicos de diferentes tecnologias. Anais do... IV Conferencia Latino Americana de Energía Solar (IV ISES CLA), 2010.

IBGE - Instituto Brasileiro de Geografia e Estatitica. Disponível em: $<$ http://www.ibge.gov.br $>$. Censo 2010. Acesso em 25 de fev. de 2013.

KASKAOUTIS, D.G.; KAMBEZIDIS, H.D.; HATZIANASTASSIOU, N.; KOSMOPOULOS, P.G.; BADARINATH, V.S. Aerosol climatology: dependence of the Angstrom Exponent on wavelength over four AERONET sites. Atmospheric Chemistry and Physics Discussions, v. 7, p. 63576411, 2007. 
KAUFMAN, Y.J.; TANRÉ, D.; BOUCHER, O. A satellite view of aerosols in the climate system Nature, v.419 p. 215-223. 2002.

LONGO, K.; THOMPSON, A.M.; KIRCHHOFF, V.W.J.H.; REMER, L.A.; FREITAS, S. R.; SILVADIAS, M.A.F.; ARTAXO, P.; HART, W.; SPINHIRNE, J.D.; YAMASOE, M.A. Correlation between smoke and tropospheric ozone concentrations in Cuiabá during SCAR-B. Journal of Geophysical Research ,104, D10, 12113-12129, 1998.

POSSANI,G.;CARBONE ,S.;PINHEIRO, D. K.; ALVALÁ, P. C.; SCHUCH, N.J. Influência de queimadas na espessura óptica de aerossóis na banda do UV no extremos sul do Brasil: 20022006. Anais do... XVI Congresso Brasileiro de Meteorologia, 2006.

RECUERO, F. S ; LONGO, K. M. ; FREITAS, S. R. Estudo do Transporte das Partículas de Aerossol de Queimada Via Sensoriamento Remoto. Anais do... XIII Congresso Brasileiro de Meteorologia, 2004, Fortaleza.

RUDORFF, B.F.T.; SHIMABUKURO, Y.E.; CEBALLOS, J.C.; O sensor MODIS e suas aplicações ambientais no Brasil. São José dos Campos, SP. Parêntese, 2007. 427p.

SCHUSTER, G.L; DUBOVIK, O; HOLBEN, B.N. The Angstrom Exponent and Bimodal Aerosol Size Distributions. Journal of Geophysical Research, v. 111, 2006.

ULKE, A.G. Regional pollution due to biomass burning in South America, Ciência e Natura, 2007.

ULKE, A.G. Aerosol characterization in Buenos Aires and relationships with transport patterns in South America, Ciência e Natura, 2009. 